\title{
DESENVOLVIMENTO DE BEBIDA PROBIÓTICA A PARTIR DE EXTRATO SOLÚVEL DE SOJA
}

\section{DEVELOPMENT OF PROBIOTIC BEVERAGE FROM SOYBEAN MILK}

\author{
Elisandra Bren ${ }^{1}$; Laís dos Santos ${ }^{1}$; Joana Valquíria Pedroso de Almeida ${ }^{1}$ \\ ${ }^{1}$ Centro de Ensino Superior dos Campos Gerais - CESCAGE - Ponta Grossa - Brasil \\ bren_elisandra@yahoo.com.br, gd.santos@yahoo.com.br, joana@ cescage.edu.br
}

\begin{abstract}
Resumo
O objetivo desta pesquisa foi desenvolver bebidas fermentadas por microrganismos probióticos em diferentes concentrações de água e extrato solúvel de soja. Foram desenvolvidas 8 formulações, sendo que 4 destas foram fermentadas individualmente por Lactobacillus acidophilus e 4 por Bifidobacterium bifidum. Após desenvolvimento destas, escolheu-se a que melhor se caracterizou como bebida e foi obtido um produto "mix" de bactérias probióticas, com índice de aceitabilidade de $81,33 \%$. Em relação à quantificação de bactérias probióticas, em todas as formulações houve crescimento superior a $10^{8} \mathrm{UFC} / \mathrm{mL} / \mathrm{g}$. A análise de $\mathrm{pH}$, mostrou que todas as formulações de bebidas apresentaram-se dentro dos padrões adequados para promover a coagulação das proteínas e conseqüente formação de gel nas bebidas.
\end{abstract}

Palavras chave: probióticos; extrato solúvel de soja; bebida probiótica fermentada.

\section{Introdução}

Alimentos funcionais são definidos pela Secretaria de Vigilância Sanitária, do Ministério da Saúde, como sendo "aquele alimento ou ingrediente que, além das funções nutritivas básicas, quando consumido como parte da dieta usual, produza efeitos metabólicos e/ou fisiológicos e/ou efeitos benéficos à saúde, devendo ser seguro para consumo sem supervisão médica" (BRASIL, RDC 18/99).

A soja e seus derivados têm recebido atenção dos pesquisadores, principalmente devido a grande quantidade e qualidade de sua proteína, sendo ela, dentre os vegetais, o melhor substituto de produtos de origem animal, além de ser uma importante fonte de fibras, oligossacarídeos com potencial prebiótico como rafinose e estaquiose, vitaminas e minerais (FUCHS et al., 2005).

Um dos mais conhecidos produtos da soja é o extrato hidrossolúvel de soja ("leite de soja"), sendo este obtido através da seleção, maceração, tratamento térmico, cocção e posterior centrifugação da semente de soja (MIYASAKA e MEDINA, 1981). 
A utilização do extrato solúvel para a fermentação de bactérias probióticas tem sido utilizada com o propósito de melhorar o sabor e aceitação do produto, pois, o sabor da soja assim como os oligossacarídeos não digeríveis são obstáculos que limitam a sua ingestão (SILVA apud KOMATSU et al., 2008),

A utilização de bactérias probióticas como os Lactobacillus acidophilus e Bifidobacterium bifidum para a fermentação do extrato solúvel de soja e obtenção de uma bebida fermentada probiótica, além de ser uma alternativa para melhorar a aceitação do produto, pode contribuir para a saúde intestinal do individuo, e conseqüentemente, estimulação do sistema imunológico, pois, conforme descrito por Ferreira e Kussakawa (1999), esses microrganismos agem por exclusão competitiva, aderindo a sítios específicos localizados no epitélio intestinal diminuindo dessa maneira a colonização por microrganismos patogênicos.

Probióticos são definidos como microrganismos vivos capazes de melhorar o equilíbrio microbiano intestinal produzindo efeitos benéficos à saúde do indivíduo (BRASIL, RDC 02/2002).

Para que um microrganismo seja considerado probiótico, deve ser habitante normal do trato gastrintestinal, sobreviver à passagem pelo estômago e manter a viabilidade e atividade no intestino, ser resistente á bílis e às enzimas pancreáticas, ter uma boa adesão às células da mucosa intestinal, ter uma boa capacidade de colonização, produzir substâncias antimicrobianas contra bactérias patogênicas e não realizar translocação (SAAD, 2006; SÁ, 2004).

Conforme descrito por Hauly et al. (2007), o extrato de soja, assim como o leite, é adequado para o crescimento de bactérias láticas. Os oligossacarídeos (rafinose e estaquiose), aminoácidos e peptídeos presentes na soja estimulam crescimento microbiano. Sendo assim a bebida fermentada de soja, obtida por meio da fermentação através da ação de microrganismos probióticos apresenta características sensoriais semelhantes às do iogurte tradicional.

Conforme recomendação da Agência Nacional de Vigilância Sanitária (2008), para um produto probiótico possa apresentar a alegação de promoção de saúde no seu rótulo, deve estabelecer a quantidade mínima viável da cultura, e esta deve estar entre $10^{8}$ a $10^{9}$ UFC (Unidades Formadoras de Colônias) por mL do produto.

Diante da procura dos consumidores por alimentos mais saudáveis, capazes de trazer benefícios extras à saúde, e dos potenciais efeitos benéficos da soja e dos probióticos, esta pesquisa teve como objetivo desenvolver bebidas a base de soja, com microrganismos probióticos, a fim de verificar a melhor combinação para aceitabilidade do produto. 


\section{Material e métodos}

Desenvolvimento das formulações de bebidas fermentadas de soja

As culturas láticas utilizadas na pesquisas foram doadas pela empresa CHR. HANSEN Valinhos/São Paulo. Sendo estas: Cultura Probiótica: Bio Rich® - fermento láctico probiótico que contém culturas selecionadas e superconcentradas de L. acidophilus LA-5 e Bifidobacterium bifidum BB-12.

Foram desenvolvidas quatro formulações com diferentes concentrações de extrato solúvel de soja e água. Cada formulação foi fermentada individualmente por L. acidophilus LA-5 e por Bifidobacterium bifidum BB-12, totalizando oito preparações. Na Tabela 1 estão apresentadas as formulações desenvolvidas.

Tabela 1 - Formulações desenvolvidas de bebidas fermentadas em extrato solúvel de soja

\begin{tabular}{|c|c|c|c|c|c|c|c|c|}
\hline \multirow[t]{2}{*}{ Ingredientes } & \multicolumn{8}{|c|}{$\begin{array}{l}\text { Formulações para } 1 \text { litro de bebida fermentada } \\
\text { (Lactobacillus acidophilus LA-5 e por Bifidobacterium bifidum BB-12) }\end{array}$} \\
\hline & \multicolumn{2}{|c|}{1} & \multicolumn{2}{|c|}{2} & \multicolumn{2}{|c|}{$\mathbf{3}$} & \multicolumn{2}{|c|}{4} \\
\hline Água & $50 \%$ & $500 \mathrm{~mL}$ & $30 \%$ & $300 \mathrm{~mL}$ & $40 \%$ & $400 \mathrm{~mL}$ & - & - \\
\hline Extrato solúvel de soja & $50 \%$ & $500 \mathrm{~mL}$ & $70 \%$ & $700 \mathrm{~mL}$ & $60 \%$ & $600 \mathrm{~mL}$ & $100 \%$ & $1000 \mathrm{~mL}$ \\
\hline Glicose & $8 \%$ & $80 \mathrm{~g}$ & $8 \%$ & $80 \mathrm{~g}$ & $8 \%$ & $80 \mathrm{~g}$ & $8 \%$ & $80 \mathrm{~g}$ \\
\hline Leite em pó & $11,50 \%$ & $115 \mathrm{~g}$ & $11,50 \%$ & $115 \mathrm{~g}$ & $11,50 \%$ & $115 \mathrm{~g}$ & $11,5 \%$ & $115 \mathrm{~g}$ \\
\hline
\end{tabular}

As concentrações dos demais ingredientes foram mantidas iguais em todas as formulações, tomando-se como valores de referência para a padronização das bebidas, as mesmas utilizadas para a produção de iogurtes tradicionais, ou seja, glicose (máximo 30\%), teor de sólidos (máximo 15\%) e bactérias probióticas (1:1) (LIMA et al., 2006; TAMINE \& ROBINSON, 1991, BEHMER, 1999).

Durante a produção das bebidas e das culturas starters, foram adotadas boas práticas de fabricação, para a segurança necessária ao produto final, evitando-se contaminações físicas, químicas e microbiológicas. As bebidas foram desenvolvidas e testadas no laboratório de técnica dietética do CESCAGE.

\section{Preparo das culturas lácticas}

As culturas lácticas liofilizadas de L. acidophilus e Bifidobacterium bifidum foram reativadas em leite longa vida integral em tempo e temperatura de produção do iogurte tradicional como recomenda Tamine \& Robinson (1991). Utilizou-se a dose recomendada pelo fabricante CHR-HANSEN, que é de $1 \mathrm{~g}$ de cultura probiótica para 1 litro de leite. Após a reativação, retirou-se $10 \mathrm{~mL}$ de cada uma das culturas e acondicionou-se em sacos plásticos distintos, num freezer em temperatura de $-18^{\circ} \mathrm{C}$, para posterior produção das bebidas fermentadas. Cada amostra de $10 \mathrm{~mL}$ de cultura produz 1 litro de bebida fermentada de extrato solúvel de soja. 
Processo de produção das bebidas

Aqueceu-se o extrato solúvel soja à temperatura de $43^{\circ} \mathrm{C}$, adicionou-se leite em pó e a glicose, (tabela 1) e $10 \mathrm{~mL}$ da cultura pura probiótica, colocou-se em estufa na temperatura de $43{ }^{\circ} \mathrm{C}$ por 6 horas para fermentação. Após a fermentação, o produto obtido foi armazenado em temperatura de refrigeração de 7-10 ${ }^{\circ} \mathrm{C}$ (TAMINE e ROBINSON 1991; PINHEIRO e PENNA 2002).

Para a determinação do $\mathrm{pH}$ nas amostras de bebidas fermentadas de soja, utilizou-se a metodologia descrita por Association, 1990; Cimiano, 1982 e Lanara, 2003.

\section{Análises microbiológicas}

Para contagem de bactérias lácticas, as metodologias foram adaptadas do Manual Técnico de Microbiologia do Instituto de Alimentos - ITAL (SILVA et al. 1995), Anderson (1992) e Compendium of Methods for the Microbiological Examination of Foods (1992).

Utilizou-se Agar de Man \& Sharp (MRS), incubou-se as placas em jarra de anaerobiose à $37^{\circ} \mathrm{C}$ por 72 horas, após esse período, realizou-se contagem microbiológica manualmente.

\section{Análise sensorial}

Aplicou-se o teste de Escala Hedônica de 9 pontos, conforme Figura 1, onde 1 correspondeu “desgostei muitíssimo" e 9 "gostei muitíssimo".

Figura 1 - Escala hedônica utilizada na análise sensorial

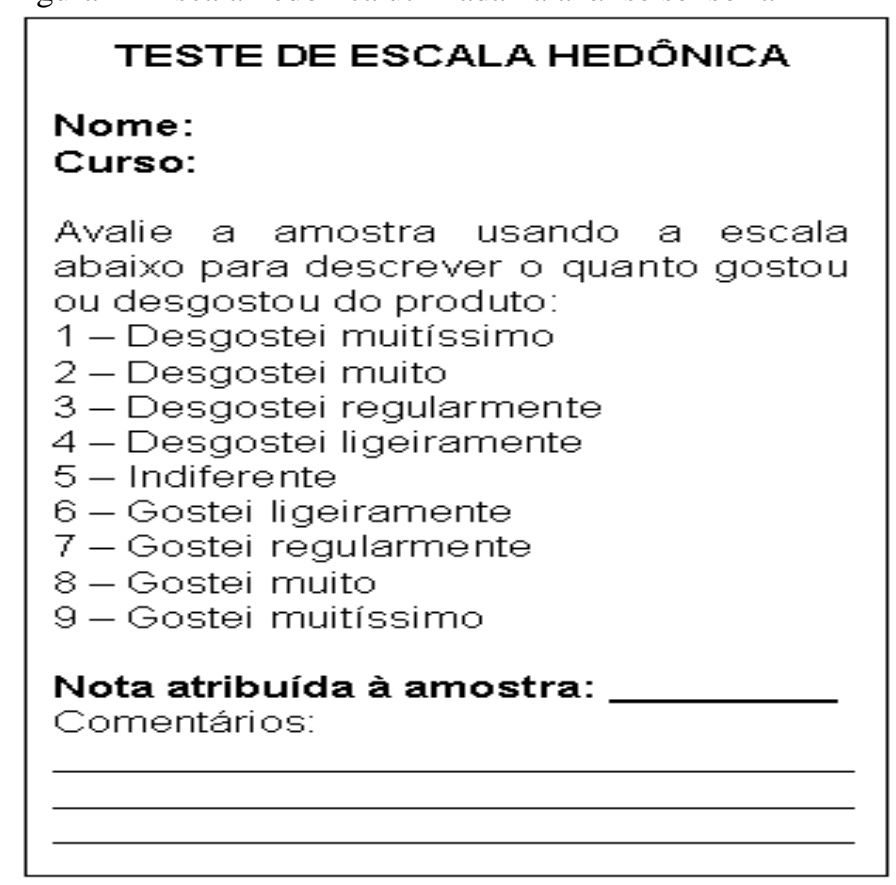

Fonte: DUTCOSKY, 1996. 
Foram recrutados 100 provadores não treinados, com idade entre 15 e 50 anos, de ambos os sexos, constituídos por funcionários e acadêmicos dos cursos superiores do CESCAGE, cuja seleção se deu por afeição ao produto, assinatura e entendimento do termo de consentimento livre, não apresentar intolerância à soja e a lactose, ter disponibilidade em participar do teste, não apresentar aversão a nenhum dos ingredientes do produto, estar tranqüilo para a realização do teste e não apresentar infecções bucais ou problemas dentários (DUTCOSKY, 1996).

O teste de aceitação do produto, o qual avalia o quanto um consumidor gosta ou desgosta de um determinado produto, foi realizado no laboratório de técnica dietética do CESCAGE onde cada provador recebeu $30 \mathrm{~mL}$ da amostra de bebida fermentada à base de extrato solúvel de soja numa temperatura de $5-8^{\circ} \mathrm{C}$, em copos plásticos com capacidade para $50 \mathrm{~mL}$, codificados com números aleatórios de 3 dígitos (DUTCOSKI, 1996).

\section{Resultados e discussão}

Desenvolvimento das formulações e valores de $\mathrm{pH}$

Nas fermentações individuais (Bifidobacterium bifidum / Lactobacillus acidophilus), o tempo de fermentação foi de 6 horas, a temperatura de $43{ }^{\circ} \mathrm{C}$. Os valores de $\mathrm{pH}$ encontrado nas bebidas após fermentação foram entre 4,4-5,0, valores que de acordo com Fuchs et al. (2005), são considerados ideais para promover a coagulação das proteínas, conseqüentemente, formação de gel. Adotou-se nesta pesquisa um valor de $\mathrm{pH}$ máximo de 5,0, os valores de $\mathrm{pH}$ para as diferentes formulações encontram-se dispostos na Tabela 2.

Tabela 2 - Valores de pH para as formulações contendo Lactobacillus acidophilus e Bifidobacterium bifidum

\begin{tabular}{cccc}
\hline Formulação & BB12 pH & LA 5 pH & Padrões Fuchs et al. (2005) \\
\hline & & & \\
1 & 4,6 & 4,70 & $4,5-5,0$ \\
2 & 4,6 & 5,0 & $4,5-5,0$ \\
3 & 5,0 & 4,5 & $4,5-5,0$ \\
4 & 5,0 & 5,0 & $4,5-5,0$ \\
\hline
\end{tabular}

Conforme descrito por Brandão (1995), o valor do pH é importante, pois, o iogurte ou bebida com baixa acidez ( $\mathrm{pH}>4,6)$ favorece a separação do soro, onde o gel não foi suficientemente formado, por outro lado, em $\mathrm{pH}<4,0$, há contração do coágulo devido à redução da hidratação das proteínas, e isso leva ao dessoramento, porém esse fenômeno não foi observado em nenhuma das formulações produzidas.

Após a produção de todas as formulações, escolheu-se a formulação de número 1 como a que melhor apresentou características de bebida, ou seja, onde o provador não necessitaria de uma colher para degustar o produto. Para a fermentação desta bebida utilizou-se as duas linhagens de microrganismos, obtendo-se uma bebida mix. 
Para a bebida mix o tempo de fermentação foi de 12 horas, isto é o dobro de tempo das formulações onde as bactérias probióticas fermentavam individualmente, isso pode ter ocorrido devido à baixa atividade de crescimento das bactérias probióticas juntas, em meios com alta quantidade protéica (OLIVEIRA \& DAMIN, 2007).

Apesar da ocorrência do fenômeno de alteração de tempo de fermentação, o pH encontrado após fermentação no produto mix foi de 4,5, estando de acordo com Fuchs et al. (2005).

\section{Análise microbiológica}

Em relação à quantificação de bactérias lácticas, a Agência Nacional de Vigilância Sanitária (ANVISA) recomenda para que ocorra a promoção da saúde e conseqüentemente efetivação dos benefícios à dose terapêutica recomendada de bactérias probióticas devem ser superiores a $10^{8} \mathrm{UFC} / \mathrm{mL}$, fato o qual foi observado em todas as bebidas produzidas, estando estas dentro destes padrões estabelecidos. Na Tabela 3 podemos observar os valores quantificados de bactérias probióticas.

Tabela 3 - Quantificação de bactérias lácticas nas amostras

\begin{tabular}{|c|c|c|c|c|c|c|c|c|c|}
\hline \multirow{2}{*}{$\begin{array}{l}\text { Formulações } \\
\text { DILUIÇŐES }\end{array}$} & \multicolumn{2}{|c|}{1} & \multicolumn{2}{|c|}{2} & \multicolumn{2}{|c|}{3} & \multicolumn{2}{|c|}{4} & \multirow{2}{*}{$\begin{array}{c}\text { MIX } \\
\text { LA } 5+\text { BB } 12\end{array}$} \\
\hline & LA5 & BB12 & LA5 & BB12 & LA5 & BB12 & LA5 & BB12 & \\
\hline $10^{-1}$ & $>250$ & $>250$ & $>250$ & $>250$ & $>250$ & $>250$ & $>250$ & $>250$ & $>250$ \\
\hline $10^{-2}$ & $>250$ & $>250$ & $>250$ & $>250$ & $>250$ & $>250$ & $>250$ & $>250$ & $>250$ \\
\hline $10^{-3}$ & $>250$ & $>250$ & $>250$ & $>250$ & $>250$ & $>250$ & $>250$ & $>250$ & $>250$ \\
\hline $10^{-4}$ & $>250$ & $>250$ & $>250$ & $>250$ & $>250$ & $>250$ & $>250$ & $>250$ & $>250$ \\
\hline $10^{-5}$ & 11 & $>250$ & 197 & 48 & $>250$ & $>250$ & 29 & $>250$ & $>250$ \\
\hline $10^{-6}$ & 11 & 114 & 25 & 14 & 38 & $>250$ & 25 & 55 & $>250$ \\
\hline $10^{-7}$ & 3 & 75 & 16 & 7 & 16 & 29 & 14 & 10 & 132 \\
\hline $10^{-8}$ & 7 & 55 & 15 & 3 & 9 & 10 & 7 & 5 & 83 \\
\hline
\end{tabular}

É primordial que as bactérias lácticas e as bactérias bífidas estejam abundantes no produto final, pois além de oferecer os benefícios discutidos nesta pesquisa, também aumentam a vida de prateleira do produto, devido à formação de compostos metabólicos como ácido láctico, ácido propiônico, diacetil, também auxiliam na formação das características específicas do produto e produzem substâncias antagônicas que exercem efeitos inibitórios nas bactérias Gram-negativas, as quais são responsáveis pela deterioração do produto (BROWN et al., 2003).

\section{Análise sensorial}

A nota média atribuída à bebida probiótica de soja pelos 100 provadores foi de 7,32. O índice de aceitabilidade da bebida foi de $81,33 \%$, o que reflete a alta aceitabilidade desse produto pelos provadores, visto que o produto é considerado aceito sensorialmente quando o índice de aceitabilidade for igual ou superior á 70\% (TEIXEIRA; MEINERT \& BARBETTA, 1987). Este teste indicou que $10 \%$ dos provadores gostaram ligeiramente da amostra, 31\% gostaram regularmente, $31 \%$ gostaram muito e $22 \%$ gostaram muitíssimo do produto. 
Em relação às notas atribuídas das escalas 1 (desgostei muitíssimo) á 5 (indiferente), 2\% desgostaram regularmente, $2 \%$ desgostaram ligeiramente, $1 \%$ foi indiferente. Essas notas podem ter sido atribuídas por pessoas que preferem produtos mais adocicados, já que a questão do teor de açúcar foi item de comentário sobre o produto. Na Figura 2 podemos observar as porcentagens de aceitabilidade do produto.

Figura 2 - Resultados de porcentagem de aceitabilidade da amostra de bebida fermentada de soja.

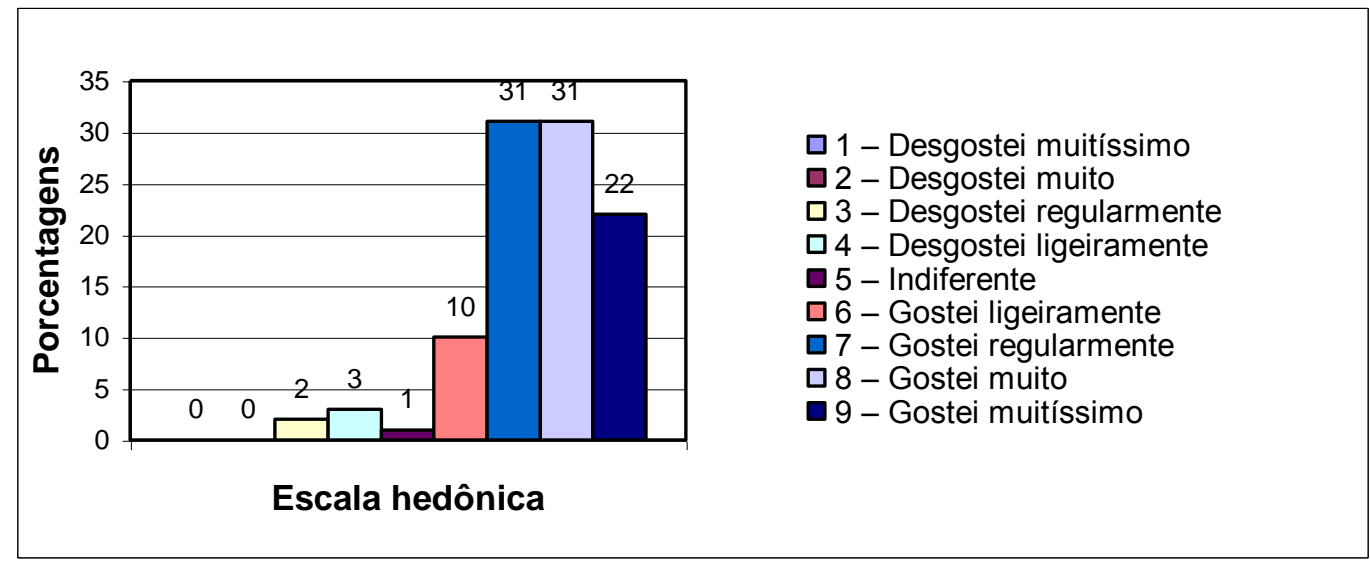

Dos cem provadores que participaram do teste, $22 \%$ fizeram comentários, sendo que $19 \%$ deles foram à relação ao sabor, que foi considerado pouco doce, $2 \%$ em relação à baixa acidez e $1 \%$ relatou que produto não agradou. .

\section{Conclusão}

O estudo realizado para pesquisa e desenvolvimento de bebidas fermentadas por bactérias probióticas em extrato solúvel de soja nos permite concluir que:

A concentração de água e extrato solúvel de soja utilizada na formulação não prejudicou a fermentação por bactérias probióticas;

A formulação de número 1, desenvolvida a partir de 50\% água, 50\% extrato solúvel de soja, $8 \%$ glicose e $11,5 \%$ de leite em pó, foi escolhida, entre as formulações desenvolvidas, como a que apresentou melhores características para a bebida em questão, sendo então, estipulada como fórmula padrão para a fermentação do mix de bactérias probióticas;

$\mathrm{Na}$ quantificação de bactérias probióticas, as culturas desenvolveram-se bem em todas as formulações, havendo crescimento adequado em 100\% das bebidas, produzidas em quantidade de microrganismos viáveis, ativos e vivos desejáveis no produto final, conforme recomendação da Agência Nacional de Vigilância Sanitária, ou seja, $10^{8} \mathrm{UFC} / \mathrm{mL} / \mathrm{g}$;

$\mathrm{O}$ índice de $\mathrm{pH}$ da bebida apresentou-se adequado, ou seja, entre 4,5 - 5,0.

O produto desenvolvido obteve $81,33 \%$ de aceitabilidade, sendo que se sugere a adaptação do dulçor da bebida, fator que será corrigido futuramente. 


\begin{abstract}
The objective of this research was to develop drunk fermented by probiotic microorganisms in different concentrations of water and soybean milk. 8 formulations were developed, and 4 of these were fermented individually by Lactobacillus acidophilus and Bifidobacterium bifidum by 4 . After development of these, the one was chosen that better it was characterized as drink... From this, we obtained a product mix of probiotic bacteria, with an index of acceptability of $81.33 \%$. in relation to the quantification of probiotic bacteria in all crops of the formulations there was superior growth the $10^{8} \mathrm{UFC} / \mathrm{mL} / \mathrm{g}$. The physical-chemical analysis of $\mathrm{pH}$ showed that all formulations of drinks were within the standards appropriate to promote the coagulation of proteins and subsequent gel formation in beverages.
\end{abstract}

Key-words: probiotics; soybean milk; fermented probiotic drink.

\title{
Referências
}

ANDERSON, M.R.P. Microbiologia Alimentaria. Cap. 15, Editora Dias Santos, Madrid, 1992.

ASSOCIATION OF OFFICIAL ANALITICAL CHEMISTS. Official Methods of analysis, 15 ed. Virginia, 1990.

BRASIL. Resolução ${ }^{\circ}$. 18, de 03 de dezembro de 1999. Regulamento técnico que estabelece as diretrizes básicas para análise e comprovação de propriedades funcionais e ou de saúde alegadas em rotulagem de alimentos. Diário Oficial da Republica Federativa do Brasil, Brasília, DF, 03 dez. 1999.

BRASIL. Resolução RDC nº. 2, de 07 de janeiro de 2002. Regulamento Técnico de Substâncias Bioativas e Probióticos Isolados com Alegação de Propriedades Funcional e ou de Saúde. Diário Oficial da Republica Federativa do Brasil, Brasília, DF, 03 dez. 1999.

BEHMER, M. L. A. Tecnologia do leite: leite, queijo, manteiga, caseína, iogurte, sorvetes e instalações: produção industrialização e análise, 13 ed verificada e atualizada, São Paulo: Nobel, 1999, pg 283-284.

Compendium of Methods for the Microbiological Examination of Foods. 3 ed. Editado por Carl Vanderzant y Don F Splittstõesser, 1992.

DUTCOSKY, S. D. Análise Sensorial de Alimentos. Editora Champagnat, p. 123, 1996.

FERREIRA, F. A. B.; KUSSAKAWA, K. C. K. Probióticos: uso de probióticos na alimentação de frangos de corte. Revista Biotecnologia Ciência e Desenvolvimento, Minas Gerais, n.8, ano II, p. 40-43, maio/jun 1999.

FUCHS, R. H. B.; BORSATO, D.; BONA E.; HAULY M. C. O. "Iogurte" de soja suplementado com oligofrutose e inulina. Ciência e Tecnologia de Alimentos, Campinas, v. 25, n. 1, 2005.

HAULY, M. C. O.; FUCHS, R. H. B.; PRUDENCIO-FERREIRA, S. F. Suplementação de iogurte de soja com frutooligossacarídeos: características probióticas e aceitabilidade. Revista Nutrição, Campinas, v. 18, n. 5, 2005.

LANARA. INSTRUÇÃO Normativa SDA n. 22, de 14 de abril de 2003.

MIYASAKA, S.; MEDINA, J. C. A Soja no Brasil. Campinas: ITAL, 1981, 1062p.

OLIVEIRA J. E.; MARCHINI J. S.; MAHAN L. K.; SCOTT-STUMP S. Revista Qualidade em Alimentação. v 2 , n. 7, jan./fev./mar.2001.

PINHEIRO, M. V. S.; PENNA, A. L. B. Aspectos tecnológicos da fabricação de iogurtes. Revista Milkbizz, Tecnologia temática laticínios, fascículo ano, n. 2, maio/junho, 2002.

SILVA, N.; JUNQUEIRA, V. C. A. Métodos de análise microbiológica de alimentos. Manual técnico, n.14, série 3, Campinas, 1995. 
SÁ, E. M. F. Os probióticos como alimentos funcionais. Revista Leite \& Derivados, São Paulo, n.79, p.42-46, ago. 2004.

SAAD, S. M. I. Probióticos e prebióticos: O estado da arte. Revista Brasileira de Ciências Farmacêuticas., v. 42 , n. $1,2006$.

TAMINE, A. Y.; ROBINSON, R. K. Yogurt: science and technology. Trad. De Maria de la Concepción Diáz de Villegas Soláns e Alvaro Rodríguz Sánchez Arévalo. Zaragoza: Acribia, 1991.

TEIXEIRA, E.; MEINERT, E. M.; BARBETTA, P. A. Métodos sensoriais. In: Análise sensorial de alimentos. Florianópolis: Editora da UFSC. p. 66-119, 1987.

Nome completo: Elisandra Bren

Filiação institucional: Centro de Educação Superior dos Campos Gerais (CESCAGE)

Departamento: Acadêmica do Curso de Nutrição

Titulação: Tecnóloga em Alimentos e Nutricionista

Endereço :Rua Teixeira Mendes 1399, Bairro Uvaranas, Ponta Grossa, Paraná, Brasil e CEP 84031 000 .

Telefones para contato: (65) 8155-7612, (42) 3226-3788

e-mail: bren_elisandra@yahoo.com.br

\section{Nome: Laís dos Santos}

Filiação Institucional: Centro de Ensino Superior dos Campos Gerais (CESCAGE)

Departamento: Departamento de Nutrição

Titulação: Mestre em Ciência e Tecnologia em Alimentos (UEPG)

Endereço: Departamento de Nutrição, Avenida General Carlos Cavalcanti, n.8000, Bairro Uvaranas, Ponta Grossa Pr, Brasil, CEP 84030-000.

e-mail: gd.santos@yahoo.com.br

\section{Nome: Joana Valquíria Pedroso de Almeida}

Filiação Institucional: Centro de Ensino Superior dos Campos Gerais (CESCAGE)

Departamento: Departamento de Nutrição

Titulação: Mestre em Ciência e Tecnologia em Alimentos (UEPG)

Endereço: Departamento de Nutrição, Avenida General Carlos Cavalcanti, n.8000, Bairro Uvaranas, Ponta Grossa Pr, Brasil, CEP 84030-000.

e-mail: joana@cescage.edu.br 